\title{
COHESIVE DEVICES IN EFL STUDENTS' EXPOSITORY WRITING
}

\author{
Hanif Nurcholish Adiantika \\ Department of English Education, Indonesia University of Education, Indonesia \\ E-mail: hanifadiantika@gmail.com
}

APA Citation: Adiantika, H. N. (2015). Cohesive devices in EFL students' expository writing. English Review: Journal of English Education, 4(1), 94-102

Published: 01-12-2015

\begin{abstract}
:
This study aims to investigate the use of cohesive devices in students' expository writing. In particular, the study focuses on types of cohesive device used by the students and how cohesive devices contribute to their writing. This study employs qualitative research through a case study design. Public senior high school in Kuningan is chosen as the site for this study. Nine students of twelfth grade are involved in the study as the respondents. Documents of nine students' expository writings are the data of this study. The data are analyzed by using the concept of cohesive devices proposed by Halliday and Hasan (1976) which covers reference, substitution, ellipsis, conjunction, and lexical cohesion. Analyses show that the respondents only use four cohesive devices in their writing i.e. reference, substitution, conjunction, and lexical cohesion. These devices also contribute to the process of keeping track of the participants, avoiding repetition and text redundancy, enhancing logical connection between parts of text, and engaging the readers to the core argument of the text. The study infers that it is still problematic although most of the students apply many cohesive devices in their writing. This is because students have not received sufficient training concerning how to use appropriate cohesive devices. Therefore, they should be guided to utilize appropriate cohesive devices in their writing.

Keywords: cohesive devices, cohesion, EFL students, expository writing, case study
\end{abstract}

\section{INTRODUCTION}

In presenting ideas in writing, students should be encouraged to make sure that their text flows through a sequence of sentences. Hence, it is fundamental to direct them to the ideas they wish to express, as well as the sentences they use to express those ideas (Holloway, 1981). In order to make the sentences readable, they should be connected to each other because a good sentence or text is not determined by its length but it depends on its connectedness and its unity (Brostoff, 1981; But et al, 2006). Therefore, EFL teachers should guide students to compose many kinds of text.
A text can either be written or spoken (Halliday and Hasan, 1976; Matthiessen, 2004; Butt et al., 2006). A text stands for a complete linguistic interaction from beginning to end as the manifestation of any instance of language that makes sense to someone who knows the language (Eggins, 1994; Halliday and Matthiessen, 2004). This suggests that the fundamental in a text is not its length or medium but its meaning or sense to be identified by its receivers. For this reason, as it is aforementioned by Halliday and Hassan (1976 cited in Eggins, 2004) text is best regarded as a semantic unit, a unit not of form but of meaning. 
Moreover, the text should have texture that makes words 'hang together' or become fixed meaningfully in a unity of text (Halliday and Hasan, 1976). It is in line with Eggins (2004), i.e. that texture refers to the interaction of two components which are called coherence and cohesion. Hence, to be a text, those minimum units of meaning should be related in a coherent and cohesive way. The coherence of the text is determined by the connection between its social and cultural contexts while cohesion is the way the text's elements are bound together as a whole. In other words, a text is a passage that becomes meaningful because its coherence and cohesion are intertwined to create the text as a whole. Texture will help readers to understand the semantic relation of the text. Furthermore, the writers' knowledge of semantic relation will potentially determine readers' comprehension (Thompson, 1996).

Hence, writers should have the ability to master the concept of texture. Cohesion is, according to Halliday and Hasan (1976), one of the crucial aspects of texture to improve the connectedness and unity of sentences in a text. It is fundamental for the students to join ideas between sentences to create texture (Halliday and Hasan, 1976). Cohesion is one of the fundamental elements of texture defined as non-structured resources for discourse to hold the text together and give the text a meaning (Halliday, 1994). Cohesive devices enable a text to preserve consistency and connectedness throughout a passage. Cohesive device are texts-specific linguistic elements employed to assemble an integrated, interpretable, and meaningful text. Cohesion is achieved through cohesive device domains, i.e. reference, ellipsis, substitution, conjunction, and lexical cohesion (Halliday and Hasan, 1976). These domains intertwine the text together into a unified whole to help the readers understand the text.

Halliday and Hasan (1976) as cited in Hoey (1991) divided cohesive devices into five categories i.e. reference, conjunction, substitution, ellipsis, and lexical cohesion. These are referred to as non-structural resources that are used in the surface structure of texts. The models of cohesion as used by Halliday and Hasan (1976) are obvious between sentences as those within the sentences can also function as structural elements. Halliday and Hasan (1983) also refer to cohesion as a semantic relation between elements in the text and some other element that is crucial to the interpretation of it.

Cohesion as described by Halliday (1976) is one of features that combine to make up the textual component in grammar. The textual components include the structural components (theme-rheme), information and focus structure (the given and new) and cohesion (grammatical and lexical). Halliday and Hasan (1976) refer to grammatical cohesion as including reference, substitution, and ellipsis while the lexical refers to the different forms of lexical cohesions. Therefore, cohesion as Halliday and Hasan (1976) describe is a semantic relation that is realized through the lexicogrammatical system. These elements as pointed out determine the texture of a text.

McArthur (1996), describes cohesion as a term derived from Latin word coheasio which means cling together. He points out that in linguistic it is the language forms used to indicate semantic relations between elements in a discourse. These relations as Halliday and Hasan (1976) describe previously are not concerned with structure (unifying 
ENGLISH REVIEW: Journal of English Education Vol. 4, Issue 1, December 2015
ISSN 2301-7554

https://journal.uniku.ac.id/index.php/ERJEE relation, part of a sentence or clause) but non-structural resources which are used for organization of a text which has been described as including reference, ellipsis, conjunction, substitution, and lexical. These are resources used to create text.

Butler (1985), in similar manner observes that Halliday and Hasan (1976) refer to cohesion as belonging to the system of a language and not simply something arising from outside, concerned merely with, for example the subject matter by text. Cook (1992) also agrees with Halliday and Hasan (1989) and Butler (1985) on the fact that cohesion is a non-structural resources used for creating texts. He refers to the cohesive devices as formal links that create relationship between sentences and clause. These formal links enable the writer to hang stretches of language together and create unity.

According to Halliday and Hasan (1976), cohesion is a semantic concept which refers to how parts of a text relate meaningfully. It has an important role to give texture to a text. It occurs where the interpretation of some element in the discourse is dependent on presence of another. Cohesion is part of the system of language and its potential lies in the systematic resource of references, ellipsis, and so on that built in language. Therefore, cohesion is not a structural relation that holds the different part of clauses, but rather is a semantic one that links text part based on their meaning relations and in such case element is interpretable by resource to another.

In other word, is defined as the way the element within a text bind it together as a unified whole (Eggins, 2004). The fundamental concept behind cohesion is a semantic tie between an item at one point in a text and an item at another point so that both items and elements are potentially integrated into the text (Halliday \& Hasan, 1976, Gerrot \& Wignell, 1994; Eggins, 2004). In other word, the ties encourage us to integrate one item for its full interpretation to another since there is a certain dependent relation between the two.

Moreover, it is stated that cohesion refers to relationship between items in a text such as words, phrases, and clauses, and other item such as pronouns, nouns, and conjunctions (Paltridge, 2006). It is supported by Carter and McCarthy (2006) that a text is cohesive as a whole if the sentences and spoken utterances are semantically linked consistently. And it will be useless if the readers or listeners are not able to see the connection of the sentence and spoken utterances.

Botley and McEnery (1996) state

that a cohesive tie occurs between a particular meaning, realized as a surface marker such as noun and noun phrase, and another instance of that meaning, realized usually by linguistic units such as pronouns and definite noun phrase. Cohesion, therefore, is achieved through cohesive ties, which can be found within or across sentences. This is also relevant with Halliday and Hasan (1976) by classifying cohesive ties into five major categories: reference, substitution, ellipsis, lexical cohesion, and conjunction, although in Halliday (1994) these cohesive ties have been reclassified into four types, with ellipsis being a subcategory of substitution.

Halliday and Hasan (1976) regard

cohesion as a semantic concept. It is mainly achieved through the availability of two types of cohesive categories, grammatical and lexical. Grammatical cohesion is created by reference, substitution, ellipsis, and conjunction. Lexical cohesion is brought by reiteration and collocation. 
Reference items are those items which are interpreted by relating them to something else instead of being interpreted semantically in their own right, or in other words, it refers to the situation where the identity of an item is retrieved from either within or outside text (Halliday, 1994, Gerot and Wignell, 1994, Salkie, 1995, Eggins, 1994;

Paltridge, 2006). In English, these items are personals (i.e. John, he, the book, it), demonstratives (i.e. here, there and comparative (i.e. fewer). Accordingly, this interpretation is achieved via two ways of reference either internal reference in which the refereed-to items are inside the text or by the aid of the outer context. In both cases a phoric relation is set up, but in each case, certain phoric relation is made. Within the text an endophoric reference is made while beyond the text borders an exophoric reference is used (Halliday \& Hasan, 1976).

Substitution occurs when one linguistic item is replaced by another that contributes new information in a text (Halliday \& Hasan, 1976). This new information differs from the information previously provided by the antecedent linguistic item. It is differentiated from reference in being concerned with wording rather than meaning (Akindele, 2011). Generally, substitution is a relation that occurs inside the text. It is a kind of strategy used to avoid repetition. As a general condition, the substitute item should have the same structural function (Halliday and Hasan, 1976).

Since substitution is a grammatical category that depends on words resources rather than on semantics, three types of substitution categories are introduced based on the function of the substitute item: these types of substitution are defined as: nominal substitution (e.g. "Pete owns the black sedan. The blue one belongs to Mike), verbal substitution (e.g. A: Has he had dinner yet? B: He must have done. There's no food in the fridge), and clausal substitution (e.g. A: Is there going to be an earthquake? B: It says so) (Halliday \& Hasan, 1976: 90).

Ellipsis happens to the syntactic and semantic components of discourse. Syntactic ellipsis is the non-expression of a word or phrase that is expected to occupy a place in the syntactic structure of a sentence. It represents the default interpretation of the term ellipsis. For example, in "Mary got an A on math test and Louise a B." the verb 'got' in the second conjunct is elided. From another hand, semantic ellipsis underlies the non-expression of items which are important to the full semantic interpretation such as in "I forgot my keys" and "He is reading Tolstoy" (McShane, 2005, p. 3; Sainton, 2006, p. 275). Thus far, Halliday \& Hasan (1976) see that ellipsis like substitution is classified into: nominal ellipsis (e.g. how did you enjoy the exhibition? - A lot () was very good, though not all), verbal ellipsis (e.g. John has caught a cold is equal with John has () a cold), and clausal ellipsis (e.g. what was the Duke going to do? () plant a row of poplars in the park.

Conjunction is the type of cohesion that involves the use of ties that perform the main function of connecting sentences (Gerrot and Wignell, 1994: 180; Paltridge, 2006: 139). Conjunction, or connective, links two ideas in a text or discourse together semantically. With the use of conjunction, the understanding of the first idea accommodates the interpretation of the second idea (Eggins, 2004: 47). In English, conjunctive relations are usually established through the use of conjunctive devices, which may be a coordinating conjunction (like and, but, 
ENGLISH REVIEW: Journal of English Education Vol. 4, Issue 1, December 2015

or), an adverb (like in addition, however, thus), or a prepositional phrase (like besides that, despite the fact that).

Halliday and Hasan (1976) and

Gerrot and Wignell (1994) divide conjunctive relations into five broad categories: additive, adversative, causal, temporal, and continuative, each of which is further divided into several subcategories. Additive relations add or substitute extra alternative clauses to a text. Adversative relation means contrary to expectation and realize through the words like yet, but, however, etc. Causal relations connect clauses as cause and effect. Temporal relations connect clauses depending on whether the actions they encode take place at the same time or one after another.

In his later work, Halliday (1994), nevertheless, classifies conjunctive elements into three broad types: elaboration, extension, and enhancement. In elaboration, one sentence elaborates on another by specifying or describing it. In extension, one sentence adds something new to another by supplying more information, replacing something or providing an alternative. Finally, in enhancement, one sentence qualifies the meaning of another by reference to time, place, manner, cause, condition, or matter.

Lexical cohesion involves the repetition of a noun phrase, or the use of another noun phrase which bears a relation to the antecedent noun phrase. Halliday and Hasan (1976) divide lexical cohesion into reiteration (which is subdivided into the repetition of a lexical item, the use of a general word to refer back to a lexical item, and the use of a synonym, or superordinate terms) and collocation. Lexical cohesion is a cohesive relation whose cohesive effect is achieved by the selection of vocabulary.
ISSN 2301-7554

https://journal.uniku.ac.id/index.php/ERJEE

According to Halliday and Hasan (1976), lexical cohesion is divided into two categories, reiteration and collocation. Reiteration is a form of lexical cohesion which involves the repletion of a lexical item. Constant repetition of lexical items would make easier for any reader to match strings in a sequence of sentences (Chan, T'Sou, Choy, 2000). The form of reiteration might be in repetition, synonymy, antonym, hyponym, and metonymy.

The study puts an emphasis on the use of cohesive devices in students' expository writing. It covers the variety of cohesive devices used by the students to create semantic relation; and to reveal the contribution of cohesive devices to students' expository writing. This study uses the concept of cohesive devices as its analytical framework, as brought forward by Halliday and Hasan (1976). Therefore, this study attempts to address the following research questions:

1) What types of cohesive devices are identified in the students' expository writing?

2) How do the cohesive devices contribute to the cohesion of students' expository writing?

\section{METHOD}

The data in this study were written documents from nine students. They wrote an expository essay in 2 hours. The instruction for students to write an exposition text is attached in Appendix. The concrete forms of the writing documents were the students' handwriting about the topic given in expository genre. The authenticity of the students' handwriting constituted the crucial data in this study. The writing documents or textual documents comprised the primary data to answer the research questions in this study. 
The primary data in form of students' expository writing were analyzed according to theoretical frameworks based on Halliday and Hasan (1976) concerning the concept of cohesive devices analysis and Eggins's point of view (1994) on cohesive ties interpretation. To analyze the data, first, the researcher separated each text based on clause. It is very fundamental to help the researcher in conducting a careful analysis since the data in this study were nine students' expository writing. Therefore, it is necessary for the researcher to cut each text into clause. Second, the identification of cohesive devices became the crucial data analysis procedure in this study. In this procedure, the researcher underlined the words belonged to cohesive devices. It is very crucial to mark the cohesive devices identified in the clause.

Third, Classification is also the crucial procedure in this study since it is inevitable that based on the framework of Halliday and Hasan (1976), cohesive devices consist of five major categories: reference, substitution, ellipsis, conjunction, and lexical cohesion. In this procedure, the researcher classified the underlined words to where they belong based on the taxonomy of cohesive devices: reference, substitution, ellipsis, conjunction, and lexical cohesion. Hence, the classification should be initiated to figure out where words belong to. The last procedure in this study was initiating descriptive quantification. Descriptive quantification is very necessary to calculate cohesive devices found in students' expository writing. This procedure was also beneficial to elaborate, enhance, and illustrate the results of the study. After the words were identified and classified, the researcher then initiated the presentation through descriptive quantification to illustrate the results for examples the frequency of occurrences of each cohesive resources.

\section{RESULTS \& DISCUSSION}

Types of cohesive devices are identified in the students' expository writing

Inside the circumstance of the use of cohesive devices, the present study shows that the cohesive devices appeared 651 times. Lexical cohesion was the mostly occurring devices with 322 occurrences. It is because, there is a tendency where students lack of vocabulary items. As a result, they overuse the lexical cohesion which is commonly realized by reiteration, in particular repetition. In addition, they seem to be fully aware of applying many repetition in their writing. It can be inferred that lexical cohesion is mostly recognizable or needed by students to cover their lack of vocabulary mastery.

It is subsequently followed by conjunction with 181 occurrences and reference with 146 appearance. Both of them are cohesive devices which the students are familiar with. The students seem to be fully aware concerning the function of conjunction and reference. Substitution is only identified in 2 occurrences in the students' expository texts. It is reasonable because the use of both substitution and ellipsis are commonly used more in speech than in writing. In other words, inside the circumstance of academic writing in particular expository writing, the use of substitution and ellipsis is rarely used by the writer.

Based on the occurrence of each cohesive device, it can inferred that students mostly applied lexical cohesion, in particular reiteration i.e. repetition to develop text's cohesion. It is subsequently followed by conjunction, reference, and substitution. On the other 
ENGLISH REVIEW: Journal of English Education Vol. 4, Issue 1, December 2015
ISSN 2301-7554

https://journal.uniku.ac.id/index.php/ERJEE hand, there is no student applied elliptical device to develop text's cohesion.

The contribution of cohesive devices to students' expository writing

According to the result of the present study, there are two aspects which are covered in the analysis, they are (1) the aspects of cohesive devices, and (2) the contributions of cohesive devices to students' exposition texts. With regard to cohesive device aspects, reference is the most frequent cohesive devices with 196 occurrences (35.1\%). It is subsequently followed by conjunction with 182 occurrences (32.6\%). Moreover, lexical cohesion occurs 179 times (32\%) and substitution with only 2 occurrences $(0.4 \%)$.

With regard to the contribution of cohesive devices to students' exposition texts, keeping track of participant gives the highest contribution with 240 occurrences $(42.9 \%)$. It is realized in the use of reference with 86 occurrences and lexical cohesion, more specifically repetition, with 154 occurrences. In order to keep track of the participants, most students apply many repetition in their writing. There is a tendency where students lack of vocabulary mastery to avoid repetition. They tend to overuse repetition. Moreover, they seem to be fully aware in using such repetitions to cover their limited vocabulary. As a result, the contribution to the process of keeping track of the participants are mostly manifested through the high use of lexical cohesion, in particular repetition.

It is subsequently followed by enhancing logical connection between parts of text systematically. This contribution is entirely realized by conjunction with 182 occurrences $(32.6 \%)$. In order to enhance logical connection between parts of texts, the students utilize many kinds of conjunction. This is because some students are familiar with the function of conjunction. However, the high use of conjunction is not in line with their texts' cohesion. Some of them were inappropriately placed. As a result, it leads to the appearances of incoherence in their texts.

It is followed by engaging the readers to the core argument of the text with 97 occurrences (17.4\%). This contribution is realized by reference which occurs 71 times, substitution with only one occurrence, and lexical cohesion with 25 occurrences. The smallest contribution is avoiding repetition and text redundancy with 40 occurrences $(7.2 \%)$. This contribution is realized by reference with 39 occurrences and substitution with only 1 occurrence. This is relevant with Halliday and Hasan (1976) that substitution is used more in speech than in writing, and more in British than American English. In other words, in the academic writing, more specifically in expository writing. That might be the reason why substitution is rarely used by the students in the present study.

\section{CONCLUSION}

According to the research questions, the purposes of the study are to identify the types of cohesive devices in the nine students' expository writing and to reveal the contribution of cohesive devices to students' expository writing based on the concept of cohesion proposed by Halliday and Hasan (1976).

First, it was found that there were only four types of cohesive devices identified in nine students' expository writing i.e. reference, substitution, conjunction, and ellipsis. Moreover, lexical cohesion is the most frequently 
used cohesive devices. It is subsequently followed by conjunction, reference, and substitution. On the other hand, no students applied ellipsis as an elliptical device to develop text's cohesion. It is in line with Halliday and Hasan (1976:117) that ellipsis and substitution are used more in speech than in writing, and more in British than American English. In other words, inside the circumstance of academic writing in particular expository writing, the use of substitution and ellipsis is rarely used by the writer. Although most of the students utilize many cohesive devices, it is still problematic since they mostly use inappropriate cohesive devices in their writing. As a result, their texts appear to be difficult to understand.

Second, it was revealed that most students utilize reference to keep track with the participants. This devices is also applied by the students to engage the readers to the core argument of the text by pointing something whether it is from within (anaphoric) or outside (exophoric) the text. In order to avoid repetition, reference (comparative reference) is also utilized by the students since it is effective to make the text less redundant. On the other hand, the contribution of conjunction to students' expository writing is to enhance logical connection between parts of the texts by expressing certain meanings which demonstrate the presence of other components in the text. Then, substitution also has a crucial substitution to avoid repetition and text redundancy by substituting one item by another. In terms of lexical cohesion, it contributes to engaging the readers to the core argument of the text. In order words, this device is used by the students to keep track with the topic of the text in particular expository text.
However, the overuse of certain cohesive devices by the students definitely causes redundancy in their writing and reduces their written texts difficult to understand. The students might be encouraged by their teacher of writing and discourse to apply as many cohesive devices as possible to conduct cohesive whole texts. This, in turn, will certainly result in less redundancy in their written texts. Moreover, unlike the English L1 users, the students mainly focus on the word and sentence level and ignore the relations of meaning that exist within the text. This relationship is achieved through relations in meaning that exist within and across sentences. The result of this tendency is the absence of connectedness which makes the flow of thoughts meaningful and clear for readers.

Therefore, cohesion is very fundamental since it gives a sequence of sentences a coherent texture as it shows how semantic relationships are set up by lexical and syntactic features. As a result, the realization of the functions of cohesion in the text will help EFL students to create meaning. It also helps the writer and readers to create communication. In other words, as it is relevant with Thompson (1996) that the writer's knowledge of semantic relation will potentially determine readers' comprehension. However, even though the cohesive devices are clearly applied by the EFL students, it is still problematic since the students may deal with some obstacles as a result of lack competence. It may also be caused by the teachers who are not able to teach them properly as the result of lack knowledge in teaching writing skill. 


\section{REFERENCES}

Brostoff, A. (1981). Coherence: "Next to" is not "connected to." College Composition and Communication, 32 (2), 278-294.

Butt, D; Fahey, R; Feez, Spinks, S; \& Yallon, C. (2006). Using Functional Grammar: An Explorer's guide. Sydney, Australia: National Centre for English Language Teaching and Research.

Buttler, C. S. (1985). Systemic Linguistics: Theory and Applications. London, England: Bats ford Academic and Educational.

Chan, S. W. K.; Thou, B. K.; and Choy, C. F. (2000). Textual Information Segmentation by Cohesive Ties. [Online]. Available: http://aclweb.org/anthology/Y/Y00 /Y00-1006.pdf. Retrieved on June 9 2015.

Cook, G. (1992). Discourse. Oxford, England: Oxford University Press.

Eggins, S. (1994). An Introduction to Systemic Functional Linguistics. London, England: Pinter Publisher.

Eggins, S. (2004). An Introduction to Systemic Functional Linguistics (2 ${ }^{\text {nd }}$ edn). London, England: Continuum.

Emilia, E. (2012). Pendekatan Genre-Based dalam Pengajaran Bahasa Inggris: Petunjuk Umum Guru. Bandung, Indonesia: Rizqi Press.

Gerot, L and Wignell, P. (1994). Making sense of Functional Grammar. Sydney, Australia: Antipodean Educational Enterprises.

Halliday, M. A. K. \& Hasan, R. (1976). Cohesion in English. London, England: Longman.

Halliday, M. A. K. (1994). Introduction to Functional Grammar. London, England: Edward Arnold.
Halliday, M. A. K., \& R.Hasan. (1989). Language, Context, and Text: Aspects of Language in a Social-Semiotic Perspective. Oxford, England: Oxford University Press.

Halliday, M.A.K. \& Christian M.I.M. Matthiessen. (2004). An Introduction to Functional Grammar. 3rd, revised edition. London, England: Edward Arnold.

Halliday, M.A.K. \& Matthiessen, C.M.I.M. (2004). An Introduction to Functional Grammar (3rd.ed.). London, England: Hodder Arnold.

Hoey, M. (1991). Patterns of lexis in text. Oxford, England: Oxford University Press.

Holloway, D. W. (1981). Semantic Grammars: How they can help us teach writing. College Composition and Communication, 32 (2), 205-218.

McArthur, T. (1996). Oxford Companion to the English Language. Oxford, England: Oxford University Press.

McCarthy, M. (1991). Discourse analysis for language teachers. Cambridge, England: Cambridge University Press.

McShane, M. J. (2005). A Theory of Ellipsis. Oxford, England: Oxford University Press.

Paltridge, B. (2006). Discourse Analysis: An Introduction. London, England: Continuum.

Sainton, R. J. (2006). Words and Thoughts: Subsentences, Ellipsis, and the Philosophy of Language. Oxford, England: Oxford University Press.

Salkie R. (1995). Text and discourse analysis. New York, NY: Routledge.

Thompson, G. (1996). Introducing Functional Grammar. London, England: Edward Arnold. 